\title{
The impact of management on the engagement and wellbeing of high emotional labour employees
}

\begin{abstract}
Australia, like many other countries, suffers high turnover of nurses and police officers. Contributions to effectively managing the turnover challenge have been called for, and there are few Australian studies of nursing/policing turnover intentions. The purpose was to examine the impact of supervisor-subordinate relationships and perceived organisational support upon engagement, wellbeing, organizational commitment and turnover intentions. Second, we examined similarities and differences between nursing and policing work contexts. The retention of nurses/police has been investigated from traditional management perspectives; however we used a different theoretical approach - Social Exchange Theory and evaluated its utility as a framework.
\end{abstract}

Findings are from Australian data collected during 2010-11 from 510 nurses and 193 police officers, using a survey-based, self-report strategy. Partial Least Squares Path Modeling was used to analyse this data. Results indicated that for both samples, engagement predicts wellbeing and then, wellbeing predicts affective commitment and intentions to leave. MANOVA results suggested that nurses had significantly higher levels of satisfaction with their supervisor-subordinate relationships, perceived organisational support, engagement, wellbeing and affective commitment, than police officers. Only the intention to leave was similar for both groups. Given that turnover can be influenced by supervisors/management, this study provides new knowledge about targeted retention strategies. 


\section{Introduction}

Australia, like many other countries, suffers high turnover of nurses and police officers. Without such important roles being competently undertaken in Australia, society is likely to suffer. Therefore, contributions to effectively managing these turnover challenges have been called for, but there are few Australian studies of nursing/policing turnover intentions. Nurses and police officers are both high emotional labour occupations, and in many OECD countries, both have higher turnover rates than other occupations. These two occupations are also similar in that both involve high levels of emotional work.

Further, the work environment for these two occupations following the implementation of New Public Management (NPM) has been characterized by high workloads, resulting from increased performance management, accountability and significantly decreased autonomy in the workplace (Ackroyd, Kirkpatrick and Walker, 2007; Diefenback 2009). However, within this workplace setting, some public sector employees perceive that they experience excessive monitoring of work and unmanageably high workloads, likely to drive thoughts of leaving.

This negative consequence is especially important for governments because the cost of educating nurses and police officers is high. Yet this situation, for nurses at least, is exacerbated by higher than average turnover rates (OECD 2009), while nurses are in short supply in many countries and one contributor is the high levels of turnover (OECD 2009).

The retention of nurses/police has been investigated from traditional management perspectives; however we used a different theoretical approach - Social Exchange Theory (SET) - as a lens to examine the impact of workplace relationships (such as the supervisorsubordinate relationship, employee engagement and wellbeing) upon work outcomes (including turnover intentions) for those employees. We also evaluated SET's utility as a framework. 
Where employees are expected to regulate their feelings and expressions in accordance with their employers' expectations when exposed to emotionally-demanding interactions (such as treating illness, attending accidents, controlling crime) on a daily basis, Hochschild (1983) termed these work roles as having emotional labour. Such roles may involve employees having to display different behaviors than those they are feeling, which can be stressful for them (Grandey, 2000; Bakker and Heuven, 2006). Consequently, such occupations tend to require a commitment to demonstrating emotions to a client that are appropriate to the job requirements. For police officers, this may mean hiding feelings of disgust and anger; for nurses, this may mean hiding feelings of sadness and/or anger for patients who are emotionally vulnerable.

Related to emotions, but different to emotional labour, is employee engagement. Engagement is conceptualized as emotional involvement, along with intellectual involvement, in creating a pervasive state of being, such that employees are energetically undertaking work tasks. However, there remains debate about how to define and conceptualize engagement (Ferguson, 2007). Saks (2006) conceptualized engagement using Social Exchange Theory (SET), which argues that reciprocity in balancing job demands and resources develops in employees that have received adequate support, resources, opportunities for promotion and other socio-emotional resources from their supervisor, leading to them displaying increased energy and dedication in undertaking work tasks.

Similarly, Shaw (2005) conceptualised engagement as part of a relationship between employees and their supervisors and/ or between colleagues and their organisation. This is the perspective adopted in this paper, which uses SET as a lens to examine the impact of workplace relationships (such as the supervisor-subordinate relationship) upon work outcomes for those employees. SET argues that when employees and supervisors develop 
effective workplace relationships, a reciprocal arrangement develops that not only benefits the individuals involved, it also benefits the organisation as a whole.

Without effective supervisor-subordinate relationships, many occupations face higher workloads, which necessitate increased emotional demands. Some researchers argue that high work demands, coupled with high emotional demands, lead to exhaustion (Bakker, 2004), whereas job resources (provided by, for example, support from supervisors) may enhance engagement and mitigate employees' intentions to leave (Bakker et al., 2007). This is particularly relevant to high emotional labour occupations, such as nursing and policing. These occupations are both key to societal stability and wellbeing, and yet both suffer from higher than average levels of turnover in many OECD countries (OECD, 2006), which is costly, both directly and indirectly to the societies they serve and their fellow occupational employees, who become over-burdened. Bakker and Heuven (2006) and Hochschild (1983) noted that police officers, as emotional workers, are exposed to emotionally demanding interpersonal interactions (such as death, illness, accidents, crimes) on a daily basis, requiring them to regulate their feelings and expressions. Similarly, nurses perform emotional labour because nurses are responsible for contributing to human relationships and the emotions within them, that understanding and dealing with emotion is a core nursing skill and that understanding, detecting and conveying emotion is pivotal to a profession that requires sensitivity within relationships (Freshwater and Stickley, 2004; Smith, Profetto-McGrath, and Cummings, 2009).

Therefore examining the impact of supervisor-subordinate relationships upon nurses' and police officers' perceptions of engagement and in turn, their wellbeing, may provide insight into whether the supervisor-subordinate relationship is adequately "cushioning" nurses and police officers from organisational demands for increased efficiency and accountability. Additionally, there are few empirical studies focussing on the impact of 
workplace relationships upon the engagement and psychological wellbeing of those occupations that involve high emotional labour. This paper provides new knowledge about this group. The primary research questions are:

1. What is the impact of supervisor-subordinate relationships and perceived organisational support upon the engagement, wellbeing, organizational commitment and turnover intentions of two examples of high emotional labour occupations?

2. What are the similarities and differences in nurses' and police officers' perceptions of supervisor-subordinate relationships and perceived organisational support and the impact upon their engagement, wellbeing, organizational commitment and turnover intentions?

The contribution of this paper is in the evidence-based knowledge about the important role of workplace support, in the form of supervisor-subordinate relationships, for those employees who have high emotional demands when dealing effectively with clients. The public expects such employees to engage effectively, and this paper identifies that a positive working environment is enhanced when there are high quality working relationships. However, without such knowledge, managers may fail to provide the level of support required to enhance retention of those working in high emotional labour jobs. We also conclude that SET is a useful framework to examine such relationships.

\section{Background}

\section{Social Exchange Theory}

SET has been used to explain numerous workplace exchange relationships. In particular, it has been used to examine the potential benefits for the employee, the supervisor and the organisation as a whole resulting from effective workplace relationships. The theory argues that when interactions between employees and their supervisors are perceived as "positive", 
over time, the outcome is a relationship based on trust of the other person and consequently, participants begin to exchange resources, knowledge, time and emotional support. Social exchanges can be studied in terms of their content or the processes involved. The content models are based on an antecedent and outcome in exchange whereas the process models focus on the development of a continuous and mutually supporting exchange between parties with both offering support and assistance in a non-sequential manner (Shore, Bommer, Rao and Seo, 2009).

The paper examines the impact of supervisor-subordinate relationships and perceived organisational support (POS) upon employees' perceptions of engagement and other outcomes and therefore it is an example of a process model of SET, because it examines the impact of the process of exchanging tangible and intangible resources between supervisors and employees (Cropanzano and Mitchell, 2005). Typical benefits of a positive relationship include access to relevant information, resources, support and participation in decisionmaking, access to interesting work assignments and greater control over workloads (Wang, Law, Hackett, Wang and Chen, 2005; Yukl, 2006). Over time, an expectation based on a reciprocal relationship exchanging tangible and intangibles develops for some employees (Wang, Law, Hackett, Wang and Chen, 2005). When poor exchanges occur, a low quality supervisor-subordinate relationship develops, which is characterised by low levels of reciprocity; instead interactions are limited to specific job tasks (Yukl and Michel, 2006).

Using the lens provided by SET, the theory suggests that in the ideal context, the ingroup would experience higher quality supervisor-subordinate relationships and perceptions of strong organisational support. Consequently, such employees would perceive themselves as supported by their supervisor plus the organisation and would perhaps perceive that their resources match their job demands. As a result, they are likely to feel engaged in (energetic 
and immersed) and committed to the workplace, which will give them perceptions of wellbeing and low desires to quit. The next section examines the concepts used in this study.

\section{Supervisor-subordinate relationships}

Supervisor-subordinate relationships can be conceptualized using Leader-Member Exchange Theory (LMX). LMX Theory is typical of workplace relationships examined using SET, and argues that supervisors do not manage all employees the same way, because the quality of "social exchanges" differs depending on the employees involved. Consequently, some LMX relationships are of a high quality and are therefore characterised by a high level of mutual support, trust and respect (Gerstner and Day 1997; Mueller and Lee 2002) where staff appear to be liked by their supervisors, irrespective of their performance (Graen and Uhl-Bien, 1995). As a result, such an "in-group" receives job resources in the form of information, support and participation in decision-making, access to interesting tasks, greater autonomy in specific jobs, promotions and bonuses. In return, supervisors receive dedicated employees who show initiative in the workplace as well as providing extra support for the supervisors' decisions (Wayne et al., 1997). In contrast to the in-group, the "out-group" (with low quality supervisor-subordinate relationships) is likely to face high job demands with inadequate job resources to cope effectively.

The LMX concept is useful in examining those occupations characterised by high emotional labour coupled with high job demands because Ackroyd et al. (2007, p.18) argued that the role of the supervisor is pivotal in buffering employees facing high job demands by providing adequate job resources. Using the SET theoretical lens suggests that the ideal situation is that all employees experience high quality LMX because this will deliver the greatest benefits to both the individual and the organisation. When supervisors are effective, then they ensure that high job demands are countered by high job resources and consequently 
employees are engaged and experience high wellbeing in the job, whereas poor quality LMX is probably characterised by job demands swamping employees until they become disengaged (Sparrowe and Linden, 1997; Wayne et al., 1997; Yrie, Hartman, and Galle, 2003).

\section{Perceived Organisational Support}

Perceived Organisational Support (POS) is defined as an employee's perception of the extent to which the organisation s/he works for values the work s/he has done and cares about her/his wellbeing (Allen, Shore and Griffeth, 2003). Just like LMX, SET is often used to examine POS because it is also based on the idea of reciprocity between employees and the organisation. That is, an employee's beliefs of how an organisation values him/her is vital for determining whether any attitudes or behaviours benefiting the organisation stem from the exchange relationship that takes place between the employee and employer (Eisenberger, Cummings, Armeli and Lynch, 1997). Further, the supervisor (perceived by employees as POS) regulates the resources for departments and for performance management systems and consequently, under ideal conditions, senior management would provide the enabling factors for enhancing employee wellbeing, and consult with supervisors and employees about the required performance outcomes.

Past research has identified supervisor support as a precursor of POS, while high affective commitment and low turnover are workplace outcomes of high levels of POS (Dawley, Houghton and Bucklew, 2010; Wayne et al., 1997). Additionally Rhoades et al. (2001) argued that high POS predicts high perceptions of wellbeing, whereas Saks (2006) argued that POS predicts the engagement of employees. In the case of nurses and police officers, where emotional demands are an everyday occurrence, the importance of providing organisational emotional support is very important in balancing competing demands (May, Gilson and Harter, 2004). Certainly, Saks (2006) suggested future research is needed to 
examine these relationships for different types of employees and to the best knowledge of the researchers, no research has yet examined, for high emotional labour occupations such as nurses and police officers, the impact of LMX and POS upon their engagement, wellbeing, affective commitment and turnover intentions. The following hypotheses are therefore proposed:

Hypothesis 1. Nurses and police officers reporting a positive organizational support culture will report higher levels of engagement.

Hypothesis 2. Nurses and police officers reporting a positive organizational support culture will report higher levels of wellbeing.

Hypothesis 3. Nurses and police officers reporting more positive exchange relationships with their supervisors will report higher levels of engagement. Hypothesis 4. Nurses and police officers reporting more positive exchange relationships with their supervisors will report higher levels of wellbeing.

\section{Employee Engagement}

Employee engagement is attracting a lot of attention by management researchers; however, to date there is a lack of empirical research findings about its antecedents and workplace outcomes (Saks, 2006). As stated, Schaufeli and Bakker (2004) proposed that there are two different psychological processes involved in developing burnout and engagement and consequently, engagement is defined in terms of state of mind characterised by positive perceptions of fulfilling tasks. In particular, Schaufeli et al. (2002) conceptualised engagement as characterised by vigor, dedication, and absorption. Vigor is categorised according to energy levels and perception of mental resilience in the workplace. Dedication is categorised in terms of employee's willingness to persistently and enthusiastically work irrespective of the difficulties encountered. Absorption is categorised according to the extent 
to which employees are happily working in the workplace (Schaufeli and Bakker, 2004, p. 295).

Past research suggests that the precursors of employee engagement are effective leadership and co-worker relationships, interesting work tasks and effective job resources (May et al., 2004). Similarly, Richman (2006) argued that engagement is likely to be influenced more by management practices, the work environment and climate, than by the age, gender or the personality of employees. In the case of teachers, high job resources were found to be effective in providing a shield against high job demands (Bakker et al., 2007). Because it is the organisation's responsibility to provide a working environment that generates and maintains employee engagement, and because recent reforms have increased the job demands of some workers such as police or nurses (Harter et al., 2002), it is expected that the engagement for these two categories of occupations requiring high emotional labour will require high organisation support as well as support from supervisors to ensure that job resources buffer job demands and wellbeing is maintained. Thus we propose:

Hypothesis 5. Nurses and police officers reporting higher levels of engagement will report higher levels of wellbeing.

\section{Psychological Wellbeing in the workplace}

Wellbeing is a broad concept used across a few disciplines and numerous authors have conceptualized wellbeing differently. For example, Keyes, Shmotki, and Ryff (2002) conceptualised wellbeing as being either subjective (capturing the balance between positive and negative and cognitive impacts) or psychological (capturing employees' mental state related to satisfaction in the job). Alternatively, Grant et al. (2007) identified three conceptualizations of wellbeing: (a) psychological wellbeing (employees' levels of satisfaction with processes and practices in the workplace), (b) physical wellbeing 
(employees' health outcomes, from stress and accidents for example) and (c) social wellbeing (the quantity and quality of workplace social networks as well as employees' perceptions of fairness and equity). In sum, wellbeing has multiple definitions, conceptualizations and measurements. In this paper, psychological wellbeing is defined as employees' attitudes and feelings about their work context (Diener, 2000) and is differentiated from job satisfaction because it encapsulates more than an employee's satisfaction with the job, and includes satisfaction with both tangible and intangible aspects of the work context.

Past researchers have identified that wellbeing affects job satisfaction (Brunetto et al. 2011a; Wright and Cropanzano, 2000) and affective commitment (Brunetto et al., 2011b). Further, LMX is a significant antecedent of wellbeing and turnover intentions (Cropanzano and Mitchell, 2005; Hodson, 2004; Thomas and Lankau, 2009). However, the relationship between LMX, POS and engagement on the one hand and the wellbeing of nurses and police officers is unclear. This is an important issue for both police officers and nurses since their high emotional investment may negatively affect wellbeing (Wright et al., 2006). It is expected that if satisfaction with LMX and POS is high, then engagement will also be high and this will in turn lead to perceptions of high levels of wellbeing, and hence, lower turnover intentions, as follows:

Hypothesis 6. Nurses and police officers reporting higher levels of wellbeing will report higher levels of affective commitment.

Hypothesis 7. Nurses and police officers reporting higher levels of wellbeing will report lower intentions to quit.

\section{Affective Commitment and Turnover Intentions}

Past research suggests a strong relationship between engaged and committed employees (Coffman and Gonzalez-Molina, 2002; Saks, 2006). Committed employees are those 
engaged in the job (Meyer and Allen, 1991). Committed employees are emotionally attached to and identify with their workplace, and consequently, they tend to want to stay working at the same organisation. POS predicts affective commitment especially when combined with a perception of justice (Luchak and Gellatly, 2007; Reid et al., 2008). Affective commitment is an important measure because Meyer and Allen (1997) and Pitt et al. (1995) found a link between employees' affective commitment and intention to leave.

While there are some empirical studies examining the affective commitment of nurses (see Brunetto et al., 2011a, b; Cohen, 2006; Rodwell et al., 2009), Dick (2010) argued that there are less studies examining the affective commitment of police officers. Further, the empirical findings about the antecedents of affective commitment in policing are inconclusive. In contrast to Noblet et al. (2009), who examined job demands and control in one Australian police agency and found that the impacts on job satisfaction and organizational commitment were inconsistent, Dick (2010) found strong support for the impact of management on affective commitment in his study of English police officers.

Both nursing and policing experience higher than average turnover levels (Buchan et al., 2004; Lynch and Tuckey, 2008) and previous research has identified a negative relationship between affective commitment and turnover intentions (Lum et al., 1998; Meyer and Allen 1997; Meyer et al., 2002). While there is a clear understanding of the antecedents of turnover intentions in the literature, few studies have focused on the antecedents of turnover intentions for those occupations that involve high emotional labour (such as police officers) (Lynch and Tuckey, 2008) and nurses. Thus, we propose a negative relationship between affective commitment and the turnover intentions for occupations involving high emotional labour:

Hypothesis 8. Nurses and police officers reporting higher levels of affective commitment will report lower intentions to quit. 


\section{The similarities and differences between nurses and police officers}

As stated, nurses and police officers are similar in that both involve high levels of emotional work and both occupations have been strongly affected by an increase in job demands because of the implementation of reforms (Ackroyd et al., 2007; Bolton, 2003). Additionally, both groups experience higher levels of turnover than many other occupations. However, they are also different in some ways. For example, in Australia and in a growing number of other OECD countries, nursing is an example of a relatively new profession (Robinson, Murrells and Clinton, 2006). Professional employees differ from other employees because of the control exercised by universities and government to regulate entry into the profession (Evetts and Buchner-Jeziorska 1997; Friedson, 2001). Consequently nurses would be expected to identify more strongly than police officers with particular beliefs and values that accompany the body of knowledge associated with with their profession (Brock, et al., 1999; Friedson, 2001; Maynard-Moody and Mushero, 2003). Because nursing is a profession, there is an expectation that their supervisors will mentor them in the job and cushion them where possible from organisational demands (Bolton, 2003). Additionally, nurses' knowledge and skills gives them more power to control their work environment (Farr-Wharton et al., 2011; Friedman, 2001) and consequently, it is expected that nurses will receive more job resources to cope with their job demands compared with police officers. Thus, we propose:

Hypothesis 9. Nurses will have higher levels of satisfaction with LMX and POS and consequently, higher levels of engagement, wellbeing and affective commitment plus lower intentions to quit, compared with police officers.

\section{Hypotheses}


Based on the literature review, the current study will contribute to the literature by examining the strength and direction of the relationships from LMX and POS of two types of emotional labour - nurses and police officers on the engagement, wellbeing, affective commitment, and turnover intention. The hypothesized relationships will be tested by using Partial Least Squares (PLS) path analysis.

\section{Methods}

\section{Sample characteristics}

The two samples (nurses and police officers) were chosen because, as mentioned previously, they are both high emotional labour occupations, and in many OECD countries, both have higher turnover rates than other occupations.

Nurses: The nurses were from 12 Australian private sector hospitals, operating in acute clinical hospital settings and experiencing similar patient case mixes. The hospital sizes comprised mainly medium (300-500 beds) and large (>500 beds) hospitals. To gather data, 1600 anonymous surveys were distributed to the 5 hospitals and nurses were invited to participate. Each survey was accompanied by a return envelope with the address of the researchers on it, to return the completed survey. Participants could choose to send that envelope or place the completed survey in the sealed envelope into a box provided at the site. The response was 510 useable surveys (response rate of $31.5 \%$ ). Of the respondents, $94 \%$ were female; $61 \%$ were aged over 45 years, $71 \%$ were registered nurses, and $55 \%$ were parttime employees. The sample is therefore representative of the nursing population in Australia, where $91 \%$ are female, $40 \%$ are aged 45 years or older, and nearly $90 \%$ are qualified nursing professionals (ABS 2005). The majority (51\%) worked in speciality wards, $15 \%$ worked in surgical wards and $20 \%$ worked in medical wards. 
Police: Police officers from one region of an Australian state police service were given surveys when attending training over a four-month period. In total, 750 surveys were distributed and we received 193 usable surveys (response rate of 26\%). The majority of the respondents were male $(\mathrm{N}=132,68.4 \%)$ and held the rank of senior constable $(31.6 \%)$. The average tenure in their current police station was less than 5 years and most have been employed with this police force for 3-10 years.

We used SmartPLS (Ringle et al. 2005), a form of latent path model, to test our path model. According to Sanchez-Franco, Martinez-Lopez and Martin-Velicia (2009), the PLS technique is primarily intended for predictive analysis. Survey data were input into SPSS v.17 for Windows to conduct descriptive statistical analysis.

\section{Measures}

We used previously validated scales to operationalize the constructs in the path model. These were measured on a six-point Likert-type scale, ranging from 1 (strongly disagree) to 6 (strongly agree).

Leader-member exchange. The leader-member exchange (LMX) validated test-bank survey traditionally measures the satisfaction of employees with the quality of the relationship with their supervisor-subordinate relationship (Mueller and Lee, 2002). In this study, a seven-item uni-dimensional scale (LMX-7), developed by Graen and Uhl-Bien (1995), was used. An example of a statement is, 'I am certain to what extent my LM will go to back me up in my decision-making.' This scale has good internal reliability as indicated by the composite reliability coefficient of 0.95 .

Perceived Organisational Support (reflective measure). Perceived organisational support was measured using Eisenberger, Cummings, Armeli, and Lynch's (1997) validated instrument. Sample items included, 'My organisation cares about my opinion'. This scale has 
a composite reliability coefficient of 0.91 and an average variance estimate of 0.58 .

Employee Engagement. We used a nine-item scale from Schaufeli and Bakker (2003) to measure Employee Engagement (formative measure). Sample items included, 'At my work, I feel bursting with energy' and 'I find the work that I do full of meaning and purpose'. A formative scale was computed by forming an additive index of the nine items. A formative scale was computed by forming an additive index of the nine items.

Affective Commitment (formative measure). We used the eight-item affective commitment scale from Allen and Meyer (1990) to measure nurses' and police officers' commitment to their organizations. Sample items included, "I feel a strong sense of belonging to my organization". A formative scale was computed by forming an additive index of the eight items.

Wellbeing. To measure Wellbeing (reflective measure), we adopted a four-item scale developed by Brunetto et al. (2011). This measure differs from others because it addresses Grant et al.'s (2007) call to include both a hedonic section (employees' perceptions of pleasure invoking either negative or positive thoughts or feelings - usually measured by employees' levels of job satisfaction) and/or a eudaimonic section (employees' perceptions of whether they have reached their potential - measured by feelings of fulfillment in reaching their goals). This measure addresses the stated criticisms (sample items include "Most days I feel a sense of accomplishment in what I do at work" and "Overall, I get enough time to reflect on what I do in the workplace"). This scale has a composite reliability coefficient of 0.90 and an average variance estimate of 0.68 .

Intention to quit. We adopted a three-item scale from Meyer, Allen and Smith (1993) to operationalize intention to quit (reflective measure), the dependent variable. Sample items included, "It is likely that I would search for a job in another organization". This scale has a composite reliability coefficient of 0.92 and an average variance estimate of 0.80 . 


\section{Validity and reliability}

The path model developed for the current study has five independent constructs and one dependent construct (sample size of 703 cases). According to Green (1991, p. 503), this is considered sufficient to achieve a medium effect size of 0.80 for path analysis. Significance of PLS parameter estimates was assessed by using the bootstrap option incorporated within the SmartPLS (Ringle et al. 2005) software. Bootstrapping with 500 sub-samples was carried out to provide extra confidence that the results were not sample-specific.

In the current study, we tested for the effect of common method bias by conducting Harman's ex-post one factor test (Podsakoff and Organ, 1986). All the variables used in the study were entered into an unrotated factor analysis. The analysis showed that there were six factors (with eigenvalues greater than 1.0), with the largest single factor explaining $37.03 \%$ of the variance. In addition, we conducted a common latent factor analysis using AMOS. The analysis showed that the common variance was less than $50 \%$. This finding provided additional confidence that common method bias was not a major concern in the current study.

We evaluated the quality of the structural model by using R-square of the dependent variable, the Stone-Geisser Q-square test for predictive relevance (Chin, 2010) and the global criterion for goodness of fit (Tenenhaus et al., 2005). Chin (2010) recommended that the communality and redundancy Q-square indices must be greater than zero, for the model to have predictive relevance. Two separate analyses with 10 and 25 omission distance were undertaken to test the stability of the findings. Since the values are stable for both omission distances and all of the Q-squares were greater than zero, we were confident that the model is stable and the predictive relevance requirement is satisfied.

\section{Results}


The model has discriminant validity as the correlation matrix shows that all the diagonal elements are greater than the corresponding off-diagonal elements (see Table 1).

[Insert Table 1 about here]

Using the formulae proposed by Tenenhaus et al. (2005) for calculating the global criterion of goodness of fit, the model has a large goodness of fit (global goodness of fit index 0.53). In addition, the path model explained 42 percent of the dependent variable, Turnover Intention. The path analysis showed that all of the paths leading from POS and LMX to turnover intention are statistically significant (see Table 3). Hence, hypotheses 1-8 were supported. Moreover, the results of the MANOVA shows that nurses are significantly more satisfied with their supervisor-subordinate relationship (LMX), Perceived organisational support (POS), employee engagement, psychological wellbeing, affective commitment compared with police officers ( $\mathrm{F}$ score $=101.695, \mathrm{p}<.001, \mathrm{df}=692$ ) (see Table 2). However, there were no significant differences in turnover intentions for nurses and police officers and therefore Hypothesis 9 was partially supported (see Table 2).

[Insert Table 2 about here]

[Insert Figure 1 about here]

\section{Discussion and Implications}

This paper had two aims. First, it examined the impact of supervisor-subordinate relationships and perceived organisational support upon the engagement, wellbeing, organizational commitment and turnover intentions of two types of high emotional labour employees. As stated, these occupations were specifically chosen because, not only are nursing and policing typical examples of occupations that require high emotional labour 
when dealing with their patients/clients on a daily basis, but also these occupations have been subject to reforms, increasing accountability and therefore their workloads. Further, they both suffer high turnover. Past research had already identified the importance of the supervisor and organisational management in buffering high job demands with high job resources (Ackroyd et al., 2007; Brunetto et al., 2010; 2011; Dick, 2010; Hoque et al., 2004). It was therefore expected that both LMX and POS would predict engagement and the findings from this study confirm that LMX and POS predict engagement. However, the findings also indicate that the higher the employees' levels of satisfaction with their supervisor-subordinate relationships and organisational support, the greater their levels of engagement.

Moreover, both LMX and POS predicted the wellbeing of nurses and police officers and as expected, engaged employees also experience perceptions of wellbeing. Additionally, wellbeing predicted both affective commitment and turnover intentions. This means that the higher the employees' perceptions of wellbeing, the higher their levels of commitment to the organisation and the lower their intentions to leave. Lastly, there was a significant inverse relationship between employees' commitment to the organisation and their intentions to quit. An important contribution of this paper is that it has used path analysis to show the link between workplace relationships and engagement and wellbeing and that these factors lead to outcomes such as commitment to the organisation and turnover intentions. Previous studies have used regressions to show relationships between these variables; in contrast, PLS is a more powerful tool, which can show predictability.

The second aim of the paper was to examine the similarities and differences in the work context of nurses and police officers by comparing their perception of supervisorsubordinate relationships, perceived organisational support, engagement, wellbeing, organizational commitment and turnover intention. The findings suggest a significantly different work context for nurses compared with police officers; however, there are some 
similarities that are disturbing. In particular, nurses have a significantly higher perception of the quality of their supervisor-subordinate relationship, as well as a higher level of engagement and wellbeing. Additionally, nurses have a significantly higher perception of POS and organisational commitment. Using the professional lens, these findings are consistent with previous findings suggesting that professional employees can expect more support from their supervisors because of the professional responsibility of supervisors to mentor and support those in the same profession (Brock et al., 2001; Farr-Wharton et al., 2011).

The alarming finding is that, while nurses and police were at least somewhat satisfied with their supervisor-subordinate relationship, neither group felt supported by their organisation (see Table 2: mean of 3.93 on a scale of 6 for nurses; 3.06 for police) - nurses were barely committed to their organisation (mean of 4.01 on scale of 6 ) and police officers were somewhat uncommitted (3.74). In terms of SET, this means that workplace relationships appear NOT to deliver the job resources from the organisation (in the form of support, time, information and assistance) required to meet the job demands experienced by nurses and police officers and the immediate outcome is that nurses and police officers are barely committed or somewhat uncommitted to their organisation.

Previous research argues that LMX and POS predict affective commitment and turnover (Brunetto et al., 2010, 2011; Rodwell et al., 2009) and wellbeing (Thomas \& Lankau 2009). There is a recognised shortage in both nursing and policing and poor management has been identified as one of the main reasons (OECD, 2006; Buchanan and Considine 2002; Dick, 2010; Secombe and Smith 1997). Consequently, the findings from this research suggest that the impact of workplace relationships (as captured by employees' satisfaction with the quality of supervisor-subordinate relationships (LMX) in particular, as well as the general level of support provided by organisational management (POS) is far from 
the ideal. In particular, the employee's perception of poor job support maybe an important reason as to why the turnover rate in higher than the average national turnover in these two high labour-high demand occupations.

Previous research suggests that management is a key to determining job resources and therefore must be an antecedent of employee engagement (May et al., 2004; Bakker et al., 2007; Harter et al., 2002), and the findings from this study suggest that this relationship is also valid for those occupations requiring high emotional labour. These findings suggest that satisfaction with the supervisor-subordinate relationship and organisational support does predict engagement.

In addition, the findings also indicate a significant difference in the engagement of nurses and police officers. One explanation could be the professional status of nurses. Past research suggests that professionals get more support from their supervisors because of their shared professional knowledge and an expectation that supervisors will mentor them and attempt to mediate the organisational and professional job demands (Brock et al., 1999; Friedson, 2001; Maynard-Moody and Mushero, 2003; Farr-Wharton et al., 2011).

Finally, using SET was found to be worthwhile as a lens through which to examine the relationships in this study. The study used a SET framework, arguing that the ideal situation is one in which nurses/police are satisfied with their relationships with their supervisors, meaning that they reciprocally share their time and other resources such as information, knowledge and skills, support and assistance. Whilst previous research has tested the relationship between LMX and organisational commitment/turnover intentions, and between training and organisational commitment/turnover intentions, few papers have examined engagement (Saks, 2006) and even fewer have examined the relationship between supervisor-subordinate relationships and engagement (May, et al., 2004). 


\section{Managerial Implications}

Organisations need effective employees who are engaged in the job and committed to achieving organisational effectiveness, and it is management's responsibility to embed effective workplace relationships to ensure that employees receive adequate job resources required to meet their job demands, so that employees can be effective. This overall notion is important because our findings suggest that the more engaged the employees, the higher the perceptions of wellbeing. Also, we found the higher the levels of satisfaction with supervisorsubordinate relationships, the higher the perceptions of wellbeing.

However, for these two occupation samples, where high emotional labour is integral to being an effective employee and for which organisational and supervisory support are essential for buffering employees' job demands, perceived support was insufficient. This means that these nurses and police officers perceived that their job demands were not matched by sufficient job resources. In other words, the findings suggest links between effective workplace relationships and nurses' and police officers' levels of engagement and wellbeing. Within the context of nurses, where the implications of poor management are evident in replacement cost (approximately double a nurse's salary) and increased patient mortality (Atencio et al., 2003), the findings suggest that high emotional labour employees need management who will deliver the job resources require for employees to balance job demands better. For the policing context, similar employee support is necessary, but the implications of not providing the required support will have different outcomes for society than for nursing. However, neither these nurses nor police officers worked in such environments. Therefore, these organisations need to demonstrate visible support for their employees. For example, HRM strategies including reasonable workloads and the fair distribution of rewards (both financial and non-financial) are needed for the effort employees put in to meet the organisations' objectives. Non-financial rewards including socio-emotional 
benefits like recognition, acknowledgement, supportive and helpful supervision are also likely to enhance perceptions of support, and thus lower turnover intentions.

For police contexts, the implications include that it may be just as important for contemporary police officers to be emotionally aware as it is for them to be physically fit and knowledgeable about the law. Hence, these findings contribute to management's understanding of what is important and required in enabling contemporary nurse and police work. These are people management problems which cannot be ignored.

One clear way to lower turnover costs is by increasing employee retention and, according to Walman, et al. (2010), the high cost of turnover is a potential opportunity to divert wasted resources towards productive outcomes. By improving working conditions, managers can increase nurse and police engagement and thereby, organisational commitment, and hence, retention. Ultimately, there are positive flow-on effects through to increased access to quality training and development, which are likely to further enhance engagement with positive outcomes for organisational commitment, and thereby, for increased retention. If management desires the retention of their valued and skilled nurses/police officers, then improving training and development appears to offer retention improvement potential.

To improve retention, our research suggests organisations may benefit greatly from ensuring both strong supervision and relationship-building capabilities in all nurse supervisors. Second, managers of healthcare or police facilities with poor retention may also consider adding improved access to quality training and development, and enabling enhanced engagement, which is likely to increase nurses' and police officers' commitment to their organisations, thereby improving retention. Third, there are other HRM strategies generally available to organisations to enhance employee engagement and wellbeing, such as rewarding employees (especially with non-financial rewards such as recognition and 
acknowledgement), providing reasonable workloads and flexible working hours, plus providing access to counselling for high emotional labour jobs such as in nursing/policing.

Further research into healthcare and police staff is warranted, including gathering qualitative data to better understand the conditions of healthcare and police workers, irrespective of sector or employment status. Also, more research is needed into the influences upon turnover intentions of part-time workers, who are likely to have less time to develop relationships with their supervisors, in order to inform prevention and interventions strategies specifically tailored to this group. Future research could also add to our results by sampling nurse/police turnover intentions from relevant organizations across several time points. These data would be particularly valuable in determining the extent to which the variables tested here will have effects over time. Similarly, future research could examine our findings to see if they hold in different contexts and occupations. Finally, research is necessary across different countries to ensure cultural bias is not present, because job performance and management vary from country to country.

\section{Limitations}

There were some limitations to this study which need to be considered. More studies are required because the age of the two groups involved was significantly different and therefore some of the identified differences between nurses and police officers could be attributed to age difference. Also, the study is limited to two types of emotional labour occupations police officers and nurses - and therefore further studies are required concerning other types of high emotional employees. Further, while this study was limited to one country and therefore should not be generalised beyond Australia, it could be argued that nurses/police working in similar environments in other countries may result in similar relationships. 
Another potential limitation is the use of self-report surveys causing common methods bias. To reduce common method bias when the criterion and predictor variable cannot be measured in different contexts, as in this study, Podsakoff et al. (2003) recommend separating the measurement of the criterion and predictor variables psychologically and ensuring the survey is anonymous. The survey applied these recommendations. In addition, we conducted a Harmon's one factor test and conducted a common latent factor analysis using AMOS, which provided additional confidence that common method bias is of no major concern in the current study.

\section{Conclusions}

This study sought to understand the path relationship of the workplace relationships available to two high emotional labour occupations on their engagement, wellbeing, commitment and turnover. The findings confirmed that LMX and POS did predict engagement and wellbeing as argued by SET. Additionally, high wellbeing was found to predict high commitment to the organisation and lower intention to quit. The contribution of the paper at a practical level is that social exchange at work causes engagement, wellbeing, affective commitment and turnover outcomes. The contribution of the paper at a theoretical level is that the findings of the paper suggest that the social exchange context is a significant antecedent of engagement and wellbeing.

Additionally, the SET framework was useful in identifying the perceived poor level of support provided by organisational management for these two categories of emotional labour. SET also provides a framework for understanding why both occupations face retention challenges. This study clearly indicates that poor levels of organisational support are perceived by employees. The findings identify the need for management practices within nursing and policing to improve the quality of social exchanges so as to provide greater 
support for ensuring that job resources match job demands, so that employees are retained and high quality services are delivered to the public. The implication for management is to link support for emotional labor with organisational retention strategies because of their impact upon turnover intentions.

The contribution of this paper is that it has identified the importance of the antecedents - supervisor and organisational support (as argued by May et al. 2004; Bakker et al, 2007; Harter et al. 2002) in predicting the engagement and wellbeing for the two emotional labour categories (nurses and police officers). Further, the findings suggest that while both nursing and policing are similar in their requirement for high emotional labour, nurses work in a significantly different work context compared with police officers. One interpretation of the findings is that being a professional affects the way the supervisorsubordinate relationship and organisational support affects engagement, wellbeing and affective commitment. In particular, it may be that being a professional means that engagement and wellbeing will be significantly higher. 


\section{References}

Ackroyd, S., Kirkpatrick, I. And Walker, R. M. (2007), 'Public Management Reform, In The UK and its Consequences for Professional Organization: A Comparative Analysis'. Public Administration, 85(1), 9-26.

Allen, N. and Meyer, J. (1990). 'The measurement and antecedents of affective, continuance, and normative commitment to the organization', Journal of Occupation Psychology, $61,1-18$.

Allen, D., Shore, L., and Griffeth, R. (2003). 'The Role of Perceived Organizational Support and Supportive Human Resource Practices in the Turnover Process'. Journal of Management, 29(1), 99-118.

Atencio, B., Cohen, J., \& Gorenberg, B (2003) 'Nurse Retention: Is it worth it'? Nursing Economics, 21 (6), 262-268

Australian Bureau of Statistics (ABS). (2005). Australian Social Trends, Catalogue 4102.0. Canberra: Australian Bureau of Statistics.

Bakker, A.B. and Heuven, E. (2006). 'Emotional dissonance, burnout, and in-role performance among nurses and police officers', International Journal of Stress Management, 13, 423-440.

Bakker, A.B. and Demerouti, E. (2007). 'The job demands - resources model: State of the art', Journal of Managerial Psychology, 22, 309 - 328.

Bakker, A. B., Demerouti, E., and Verbeke, W. (2004). 'Using the job demands-resources model to predict burnout and performance'. Human Resource Management, 43, 83104.

Bakker, A. B., and Demerouti, E. (2007). 'The job demands-resources model: State of the art'. Journal of Managerial Psychology, 22, 309-328. 
Bakker, A.B. and Heuven, E. 2006. 'Emotional dissonance, burnout, and in-role performance among nurses and police officers', International Journal of Stress Management, 13, 423-440.

Bolton, S. (2003). "Multiple roles? Nurses as managers in the NHS." International Journal of Public Sector Management 16(2), 122-130.

Brock, D., Powell, M., and Hinings, C. (eds.) (1999), Restructuring the Professional Organization: Accounting, Healthcare and Law, London: Routledge.

Brunetto, Y., Farr-Wharton, R., and Shacklock, K (2010) 'The impact of supervisorsubordinate relationships on public and private sector nurses' commitment, Human Resource Management Journal, 20 (2), 206-225.

Brunetto, Y., Farr-Wharton, R., and Shacklock, K. (2011a). 'Using the Harvard HRM model to conceptualise the impact of changes to supervision upon HRM outcomes for different types of public sector employees'. International Journal of Human Resource Management, 22 (3), 553-573.

Brunetto, Y., Farr-Wharton, R., and Shacklock, K. (2011b). 'Supervisor-nurse relationships, teamwork, role ambiguity and wellbeing: public versus private sector nurses'. Asia Pacific Journal of Human Resources, 49(2), 143-64.

Buchan, J., and Calman, L. (2004). The global shortage of registered nurses: An overview of issues and Actions. Geneva, International Council of Nurses.

Chin, W. W. (2010). 'How to write up and report PLS analyses', In W. W. Chin (Ed.), Handbook of Partial Least Squares Analysis: Concepts, Methods and Applications: 645-688. Berlin Heidelberg: Springer.

Coffman, C. and Gonzalez-Molina, G. (2002). Follow This Path: How the World's Greatest Organizations Drive Growth by Unleashing Human Potential. New York: Warner. 
Cohen, J. (2006). 'The aging nursing workforce: how to retain experienced nurses,' Journal of Healthcare Management, 51, 4, 233-246.

Cropanzano, R. and Mitchell, M.S. (2005). "Social exchange theory: an interdisciplinary review", Journal of Management, 31, 874-900.

Dawley, D., Houghton, J. D., and Bucklew, N. S. (2010). 'Perceived organizational support and turnover intention: The mediating effects of personal sacrifice and job fit'. The Journal of Social Psychology, 150(3), 238-57.

Dick G (2010). 'The influence of managerial and job variables on organizational commitment in the police'. Public Administration, doi: 10.1111/j.1467-9299.2010.01874.x

Diefenbach, T. (2009). 'New public management in public sector organizations: the dark sides of managerialistic 'enlightenment'.' Public Administration 87, 4, 892-909.

Diener, E. (2000). 'Subject wellbeing: The science of happiness, and a proposal for a national index', American Psychology, 55, 34-43.

Eisenberger, R., Cummings, J., Armeli, S., and Lynch, P. (1997). 'Perceived organizational support, discretionary treatment, and job satisfaction'. Journal of Applied Psychology, 82(5), 812-820.

Evetts, J., and Buchner-Jeziorska, A. (1997), 'Professionalism in European Markets: The International Order of Engineering in the UK and Poland,' Policy Studies, 18(3), 239249.

Farr-Wharton, R., Brunetto, Y., and Shacklock, K. (2011). 'Professionals' supervisorsubordinate relationships, autonomy and commitment: A leader-member exchange theory perspective'. International Journal of Human Resource Management, 22(17), 3496-3512. 
Ferguson, A. E. (2007). 'Employee engagement: What it is, and how does it work in business and medical settings'. Paper presented at the Australian Industrial and Organisational Psychology Conference: Better Work Better World, Adelaide.

Fornell, C. and Larcker, D. F. (1981). 'Evaluating structural equation models with unobservable variables and measurement error', Journal of Marketing Research, 18, $39-50$.

Freshwater, D. and Stickley, T., (2004). 'The heart of the art: emotional intelligence in nurse education'. Nursing Inquiry 11, 91-98.

Friedson, E. (2001), Professionalism: The Third Logic, Chicago, IL: University of Chicago Press.

Gerstner, C., and Day, D. (1997), 'Meta-Analytic Review of Leader-Member Exchange Theory: Correlates and Construct Issues,' Journal of Applied Psychology, 82, 827844.

Graen, G., and Uhl-Bien, M. (1995), 'Relationship-based approach to leadership: Development of leader-member exchange (LMX) theory of leadership over 25 years: Applying a multi-level multi-domain perspective,' Leadership Quarterly, 6(2), 219247.

Grandey, A. (2000). 'Emotion regulation in the workplace: A new way to conceptualize emotional labor'. Journal of Occupational Health Psychology, 5, 95-110.

Grant, A. M., Christianson, M. K., and Price, R. H. (2007). 'Happiness, health, or relationships? Managerial practices and employee well-being tradeoffs', Academy of Management Perspectives, 21, 51-63.

Green, S. B. (1991). 'How many subjects does it take to do a regression analysis?' Multivariate Behavioral Research, 26, 499-510. 
Harter, J., Schmidt, F., and Hayes, T. (2002). 'Business-unit-level relationship between employee satisfaction, employee engagement, and business outcomes: A metaanalysis', Journal of Applied Psychology, 87, 268 - 279.

Hartmann, L. C. and Bambacas, M. (2000). 'Organizational commitment: A multi method scale analysis and test of effects', International Journal of Organizational Analysis, 8, 89-108.

Hochschild, A. (1983). The Managed Heart: Commercialization of Human Feeling. Berkeley: University of California Press.

Hodson, R. (2005). 'Management behavior social capital: A systematic analysis of organizational ethnographies'. British Journal of Industrial Relations, 43, 41-65.

Hoque, Z., Arends, S., and Alexander, R. (2004). 'Policing the police service: A case study of the rise of "new public management" within an Australian police service', Accounting, Auditing and Accountability Journal, 17, 59-84.

Isen, A. M. (2003). Positive affect as a source of human strength. In L. G. Aspinwall, and U. M. Staudinger (Eds.), A psychology of human strengths: Fundamental questions and future directions for a positive psychology. (pp. 179-195). Washington, DC: American Psychological Association.

Keyes, C., Shmotkin, D., and Ryff, C. (2002). 'Optimizing well-being: The empirical encounter of two traditions'. Journal of Personality and Social Psychology, 82(6), 1007-1022.

Kirkpatrick, I., Ackroyd, S., and Walker, R. (2004). The New Managerialism and Public Service Professions. London: Palgrave.

Long, M. (2003). 'Leadership and performance management', In T. Newburn (Ed.), Handbook of Policing, pp. 625-658. Devon UK: Willan Publishing Ltd. 
Luchak, A. and Gellatly, I. (2007). 'A comparison of linear and nonlinear relations between organizational commitment and work outcomes', Journal of Applied Psychology, 92, 786-793.

Lum, L., Kervin, J., Clark, K., Reid, F., and Sirola, W. (1998). 'Explaining nursing turnover intent: Job satisfaction, pay satisfaction, or organizational commitment? 'Journal of Organizational Behavior, 19, 305-320.

Lynch, J.E. and Tuckey, M. (2008). 'The police turnover problem: Fact or fiction?' Policing: An International Journal of Police Strategies and Management, 31, 6-18.

May, D., Gilson, R., and Harter, L. (2004). 'The psychological conditions of meaningfulness, safety and availability and the engagement of the human spirit at work', Journal of Occupational and Organizational Psychology, 77, 11- 37.

Maynard-Moody, S., and Mushero, M. (2003), Cops, Teachers, Counselors: Stories from the Front Lines of Public Service, Ann Arbor, MI: University of Michigan Press.

Meyer, J. and Allen, N. (1997). Commitment in the Workplace: Theory, Research and Application. Thousand Oaks: Sage Publications.

Meyer, J. P. and Allen, N. J. (1991). 'A three-component conceptualization of organizational commitment', Human Resource Management Review, 1, 61-89.

Meyer, J. P., Stanley, D. J., Herscovitch, L., and Topolnytsky, L. (2002). ‘Affective, continuance, and normative commitment to the organization: A meta-analysis of antecedents, correlates, and consequences', Journal of Vocational Behavior, 61, 2052.

Meyer, J. P., Allen, N. J., and Smith, C. A. (1993). 'Commitment to organizations and occupations: extension and test of a three component conceptualization', Journal of Applied Psychology, 78, 538-551. 
Mueller, B., and Lee, J. (2002). 'Leader-member exchange and organizational communication satisfaction in multiple contexts,' Journal of Business Communication, 39(2), 220-244.

Noblet, A., J. Rodwell and Allisey, A. (2009). 'Job stress in the law enforcement sector', Stress and Health, 25, 111-120.

OECD (2006). Live Longer, Paris: OECD.

Pitt, M., Leyland, F., Foreman, S. K., and Bromfield, D. (1995). 'Organisational commitment and service delivery: Evidence from an industrial setting in the UK', International Journal of Human Resource Management, 6, 369-389.

Podsakoff, P. M. and Organ, D. W. (1986). 'Self-reports in organizational research: Problems and prospects', Journal of Management, 12, 531-544.

Podsakoff, P. M., MacKenzie, S. B., Lee, C. A., and Podsakoff, N. P. (2003). 'Common method biases in behavioral research: A critical review of the literature and recommended remedies', Journal of Applied Psychology, 88, 879-903.

Reid, M. F., Riemenschneider, C. K., Allen, M. W., and Armstrong, D. J. (2008). 'Information technology employees in state government: A study of affective organizational commitment, job involvement, and job satisfaction', American Review of Public Administration, 38, 41-61.

Rhoades, L., Eisenberger, R., and Armeli, S. (2001).'Affective commitment to the organization: The contribution of perceived organizational support'. Journal of Applied Psychology, 86, 825-836.

Richman, A. (2006). 'Everyone wants an engaged workforce, how can you create it?' Workspan, 49, 36-39.

Ringle, C. M., Wende, S., and Will, A. SmartPLS 2.0 (beta); www.smartpls.de [Accessed January 2012]. 
Robinson, S., Murrells, T. and Clinton, M. (2006). 'Highly qualified and highly ambitious: implications for workforce retention of realising the career expectations of graduate nurses in England'. Human Resource Management Journal, 16(3), 287-312.

Rodwell, J., Noblet, A., Demir, D. and Steane, P. (2009). 'Supervisors are central to work characteristics affecting nurse outcomes'. Journal of Nursing Scholarship, 41(3), $310-319$.

Saks, A. M. (2006). 'Antecedents and consequences of employee engagement', Journal of Managerial Psychology, 21, $600-619$.

Sanchez-Franco, M., Martinez-Lopez, F., and Martin-Velicia F. (2009). 'Exploring the impact of individualism and uncertainty avoidance in Web-based electronic learning: An empirical analysis in European higher education', Computers and Education, $52(3), 588-598$.

Schaufeli, W. and Bakker, A. (2003). UWES Utrecht Work Engagement Scale. Preliminary Manual, Utrecht University: Occupational Health Psychology Unit.

Schaufeli, W. B., and Bakker, A. B. (2004). 'Job demands, job resources and their relationship with burnout and engagement: A multi-sample study'. Journal of Organizational Behavior, 25, 293-315.

Schaufeli, W. B., Salanova, M., Gonzalez-Romá, V., and Bakker, A. B. (2002). 'The measurement of engagement and burnout: A confirmative analytic approach'. Journal of Happiness Studies, 3, 71-92.

Shaw, K. (2005). 'An engagement strategy process for communicators'. Strategic Communication Management, 9(3), 26-29.

Shore, L, Bommer, W., Rao, A., and Seo, J. (2009). 'Social and economic exchange in the employee-organization relationship: the moderating role of reciprocation wariness'. Journal of Managerial Psychology, 24(8), 701-721. 
Smith, K. B., Profetto-McGrath, J., and Cummings, G. G. (2009). 'Emotional intelligence and nursing: An integrative literature review'. International Journal of Nursing Studies, 46, 1624-1636.

Sparrowe, R. and Linden, R. (1997). 'Process and structure in leader-member exchange'. Academy of Management Journal, 22(2), 522-552.

Tenenhaus, M., Vinzi, V. E., Chatelin, Y.-M., and Lauro, C. (2005). 'PLS Path Modeling', Computational Statistics and Data Analysis, 48, 159-205.

Thomas, C. H. and Lankau, M. J. (2009). 'Preventing burnout: The effects of LMX and mentoring on socialization, role stress, and burnout'. Human Resource Management, 48(3), 417-432.

Waldman, J. D., Kelly, F., Arora, S., \& Smith, H. L. (2010). 'The shocking cost of turnover in health care'. Health Care Management Review, 35(3), 206-211.

Wang, H., Law, K., Hackett, R., Wang, D., and Chen, Z. (2005). 'Leader-member exchange as a mediator of the relationship between transformational leadership and followers' performance and organizational citizenship behavior'. Academy of Management Journal, 48(3), 420-432.

Wayne, S. J., Shore, L. M., and Liden, R. C. (1997). 'Perceived organizational support and leader-member exchange: A social exchange perspective'. Academy of Management Journal, 40, 82-111.

Wright, T. A. and Cropanzano, R. (2000). 'Psychological well-being and job satisfaction as predictors of job performance', Journal of Occupational Health Psychology, 5, 84-94.

Wright, R., Powell, M.B., and Ridge, D. (2006). 'Child abuse investigation: An in-depth analysis of how police officers perceive and cope with daily work challenges'. Policing: An International Journal of Police Strategies and Management, 29, 498-512 
Yrie, A., Hartman, S. and Galle, W. (2003). 'Examining communication style and leadermember exchange: considerations and concerns for managers', International Journal of Management, 20(1), 92-100.

Yukl, G., and Michel, J. W. (2006). 'Proactive influence tactics and leader member exchange'. In C. A. Schriesheim and L. L. Neider (Eds.), Power and influence in organizations (pp. 87-103). Greenwich, CT: Information Age Publishing.

Yukl, G. (2010). Leadership in organizations (7th ed.). Upper Saddle River, NJ: Pearson Prentice Hall. 


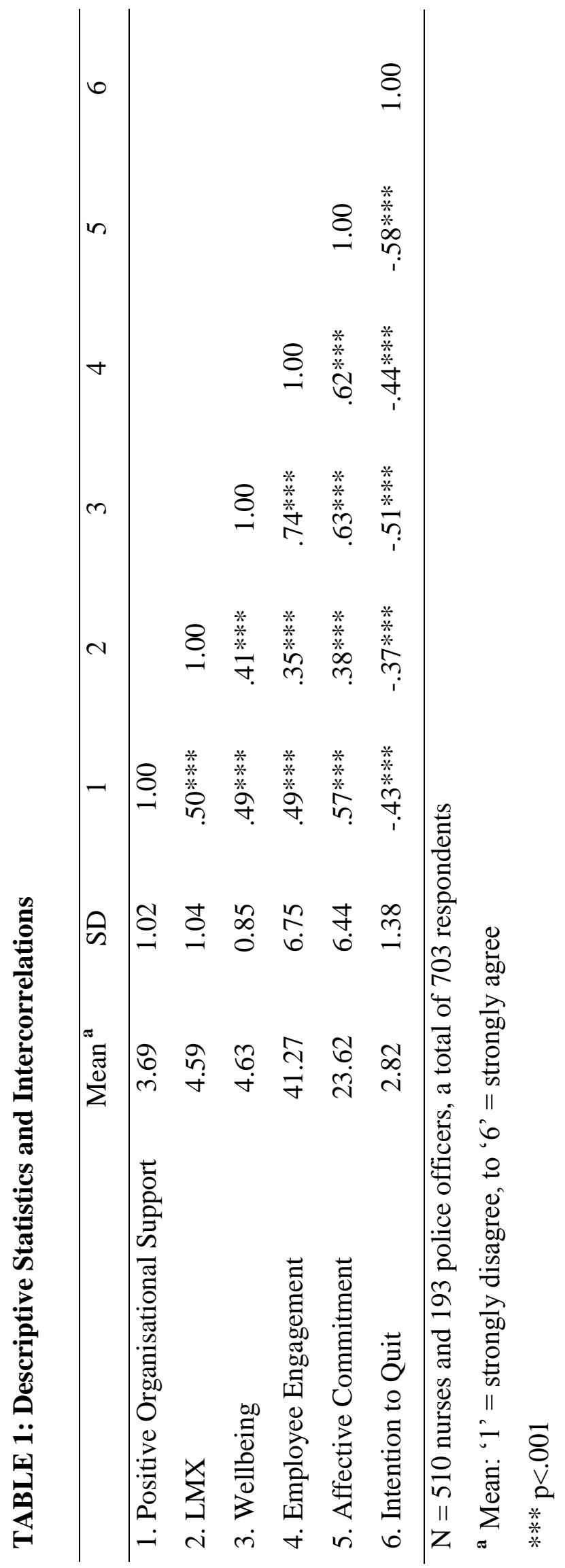




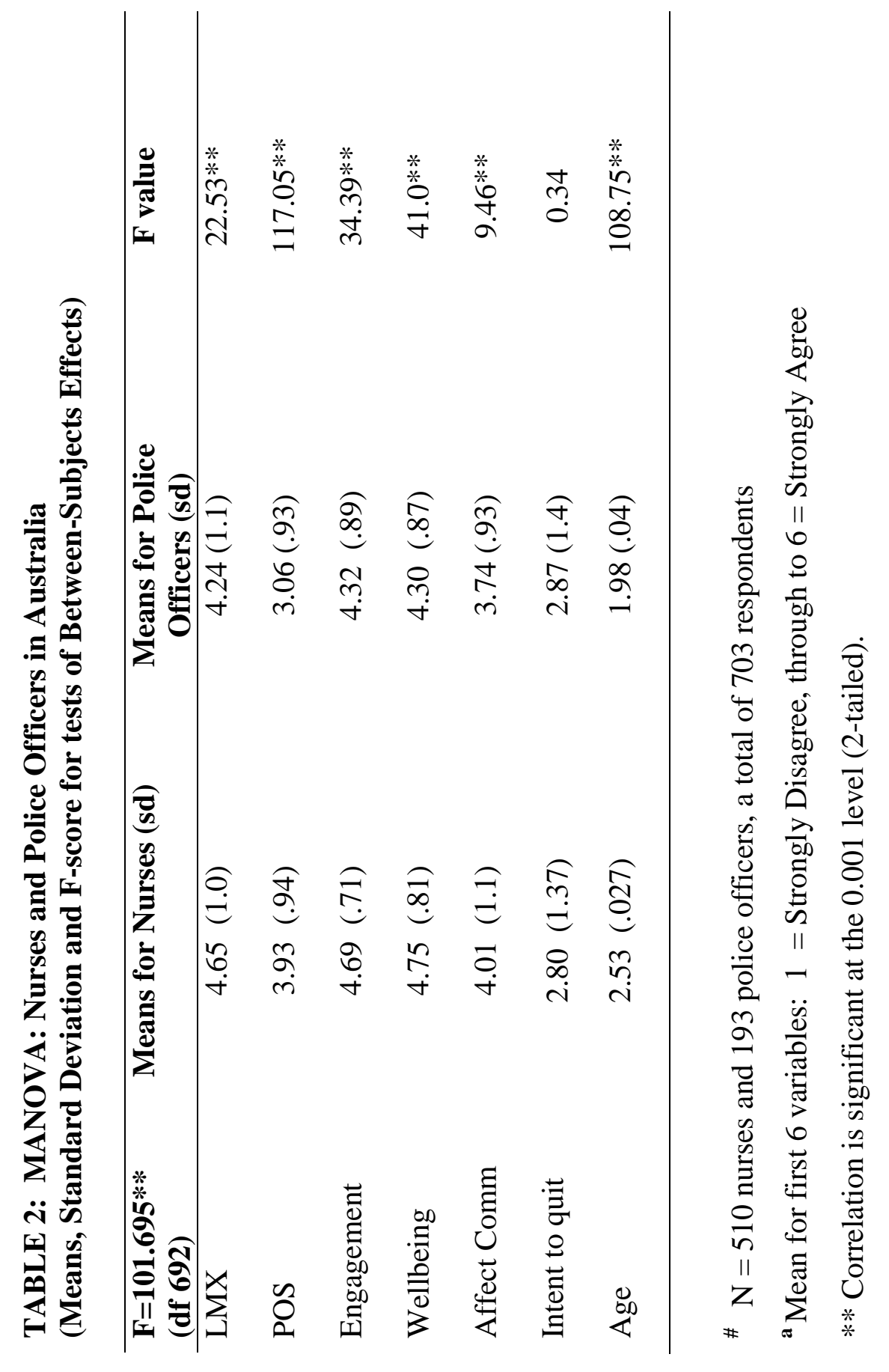




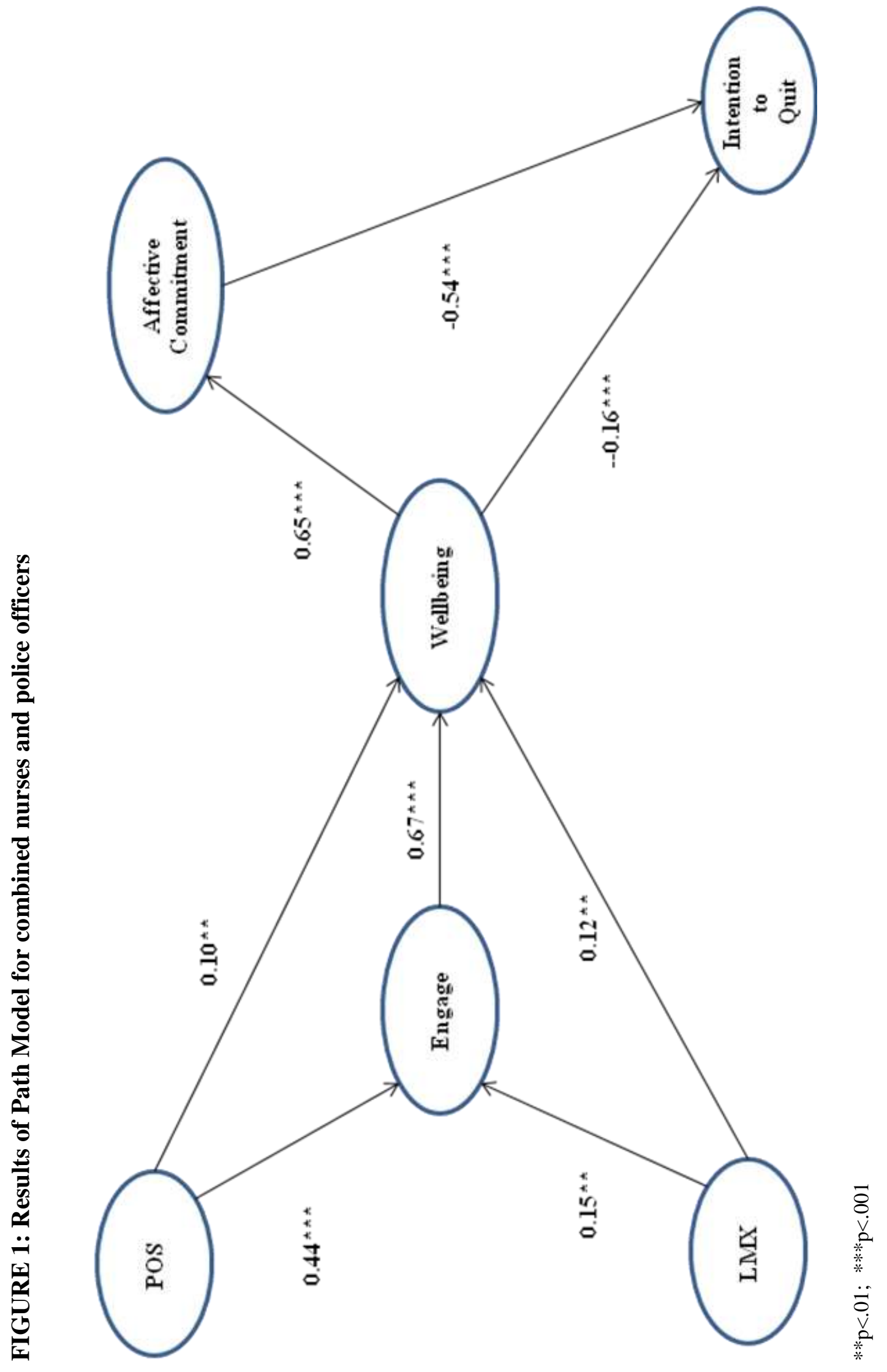

ले 
TABLE 3: Results of Path Analysis for Combined Population

\begin{tabular}{|l|c|c|}
\hline \multicolumn{1}{|c|}{ Hypotheses } & $\begin{array}{c}\text { path } \\
\text { coefficient }\end{array}$ & t-statistic \\
\hline $\begin{array}{l}\text { H1: Employees reporting a positive organizational } \\
\text { support culture will report higher levels of engagement. }\end{array}$ & 0.44 & $11.36^{* * *}$ \\
\hline $\begin{array}{l}\text { H2: Employees reporting a positive organizational } \\
\text { support culture will report higher levels of wellbeing. }\end{array}$ & 0.10 & $3.33^{* * *}$ \\
\hline $\begin{array}{l}\text { H3: Employees reporting more positive exchange } \\
\text { relationships with their supervisors will report higher } \\
\text { levels of engagement. }\end{array}$ & 0.15 & $3.27 * *$ \\
\hline $\begin{array}{l}\text { H4: Employees reporting more positive exchange } \\
\text { relationships with their supervisors will report higher } \\
\text { levels of wellbeing. }\end{array}$ & 0.12 & $3.53^{* * *}$ \\
\hline $\begin{array}{l}\text { H5: Employees reporting higher levels of engagement } \\
\text { will report higher levels of wellbeing. }\end{array}$ & 0.67 & $20.25^{* * *}$ \\
\hline $\begin{array}{l}\text { H6: Employees reporting higher levels of wellbeing will } \\
\text { report higher levels of affective commitment. }\end{array}$ & 0.65 & $25.01 * * *$ \\
\hline $\begin{array}{l}\text { H7: Employees reporting higher levels of wellbeing } \\
\text { will report lower intentions to quit. }\end{array}$ & -0.16 \\
\hline $\begin{array}{l}\text { H8: Employees reporting higher levels of affective } \\
\text { commitment will report lower intentions to quit. }\end{array}$ & $3.66^{* * *}$ \\
\hline
\end{tabular}

$\mathrm{N}=703$

$* * \mathrm{p}<.01 ; * * * \mathrm{p}<.001$ 